\title{
Gold as an intraocular foreign body
}

\author{
S. C. SEN AND ABHIJIT GHOSH \\ From the Regional Institute of Ophthalmology, Medical College, Calcutta-700073, India
}

SUMMARY A case of a gold particle remaining as an intraocular foreign body in the anterior chamber for $91 / 2$ years is reported. The 22-carat gold particle, containing a small amount of copper, did not cause any irritation to the eye.

Most intraocular metallic foreign bodies are iron and steel or one of their alloys. To our knowledge gold as an intraocular foreign body has not yet been reported. One such case is reported here.

\section{Case report}

In November 1972 a 26-year-male, a goldsmith of Midnapore, West Bengal (150 km from Calcutta), was preparing small golden hollow balls with a blowpipe, when he received an accidental injury to his right eye from the explosion of an overheated ball. He was treated with chloramphenicol eye ointment by a local doctor. Because of the visible foreign body in the anterior chamber he was referred to one of us.

On examination of the right eye on the third day of injury, slight conjunctival congestion was found in the lower part of the eye. An oblique linear wound about $3 \mathrm{~mm}$ in length was seen at the limbus at 6 o'clock. There was no prolapse of the iris. An irregularly quadrilateral flat foreign body about $2 \times 2$ $\mathrm{mm}$ with golden lustre was seen at the bottom of the anterior chamber, which was of normal depth. No other abnormality was detected on detailed examination with a slit-lamp. Vision was 6/9.

As metallic gold is inert to human tissue, and there was no sign of irritation in the injured eye, and wound margins at the limbus were in perfect apposition, we decided to treat the case with local antibiotics only. Within a few days the congestion disappeared completely. As there was no complication in the eye, the patient was allowed to return home, with the advice to report again if there was any trouble. But he never contacted us.

However, in May 1982 we were able to re-examine the patient. The right eye was quiet. There was nothing abnormal except a small, oblique, linear scar of the cornea near the limbus at 6 o'clock and a Correspondence to Professor S. C. Sen. shining, flat, roughly quadrilateral foreign body with a golden lustre at the bottom of the anterior chamber near 6 o'clock without any evidence of past inflammation in the anterior segment anywhere (Fig. 1). Vision was $6 / 6$, the ocular media were clear, and the fundus was healthy. The other eye was normal.

\section{Discussion}

As pure gold is too soft, it is alloyed with copper for the preparation of ornaments. In this case 22-carat gold was used for the manufacture of golden balls. It consisted of $91.75 \%$ pure gold and $8.25 \%$ copper. If copper is present in the form of a dilute alloy, it tends to be disposited in various membranes of the eye, producing the picture of chalcosis. ${ }^{12}$ Irritation of the eye was reported by Wardrop in 1826 as following introduction of gold contamined with copper or zinc into the globe. ${ }^{3}$ But in the present case, though the gold alloy consisted $8.25 \%$ of copper and remained within the globe for $91 / 2$ years, it did not cause any irritation, and there was no evidence of deposition of metallic copper anywhere in the eye.

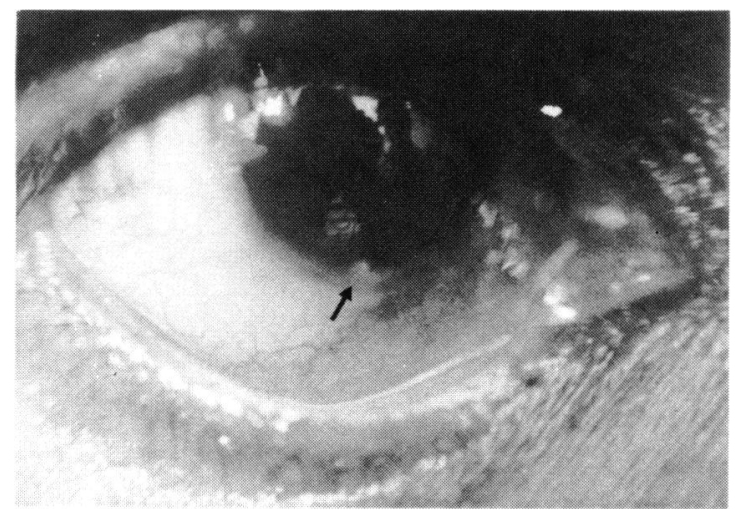


2 Sorsby A. Modern ophthalmology. London: Butterworth, 1972: 3: 472.

1 Duke-Elder S, MacFaul PA. In: Duke-Elder S. System of ophthal- 3 Wardrop (1826). Cited by Duke-Elder S, MacFaul PA. System of mology. London: Kimpton, 1972: 14: 512. ophthalmology. London: Kimpton, 1972: 14: 508. 